\title{
Entrepreneurial Leadership in the Micro and Small Enterprises (MSES) Research Context: A Literature Review
}

\author{
Suraiya Ishak, Ahmad Raflis Che Omar, Azima Abd. Manaf
}

To Link this Article: http://dx.doi.org/10.6007/IJARBSS/v11-i5/9815

DOI:10.6007/IJARBSS/v11-i5/9815

Received: 21 March 2021, Revised: 24 April 2021, Accepted: 06 May 2021

Published Online: 20 May 2021

In-Text Citation: (Ishak et al., 2021)

To Cite this Article: Ishak, S., Omar, A. R. C., \& Manaf, A. A. (2021). Entrepreneurial Leadership in the Micro and Small Enterprises (MSES) Research Context: A Literature Review. International Journal of Academic Research in Business and Social Sciences, 11(5), 397-403.

\section{Copyright: @ 2021 The Author(s)}

Published by Human Resource Management Academic Research Society (www.hrmars.com)

This article is published under the Creative Commons Attribution (CC BY 4.0) license. Anyone may reproduce, distribute, translate and create derivative works of this article (for both commercial and non-commercial purposes), subject to full attribution to the original publication and authors. The full terms of this license may be seen at: http://creativecommons.org/licences/by/4.0/legalcode

Vol. 11, No. 5, 2021, Pg. 397 - 403

Full Terms \& Conditions of access and use can be found at http://hrmars.com/index.php/pages/detail/publication-ethics 


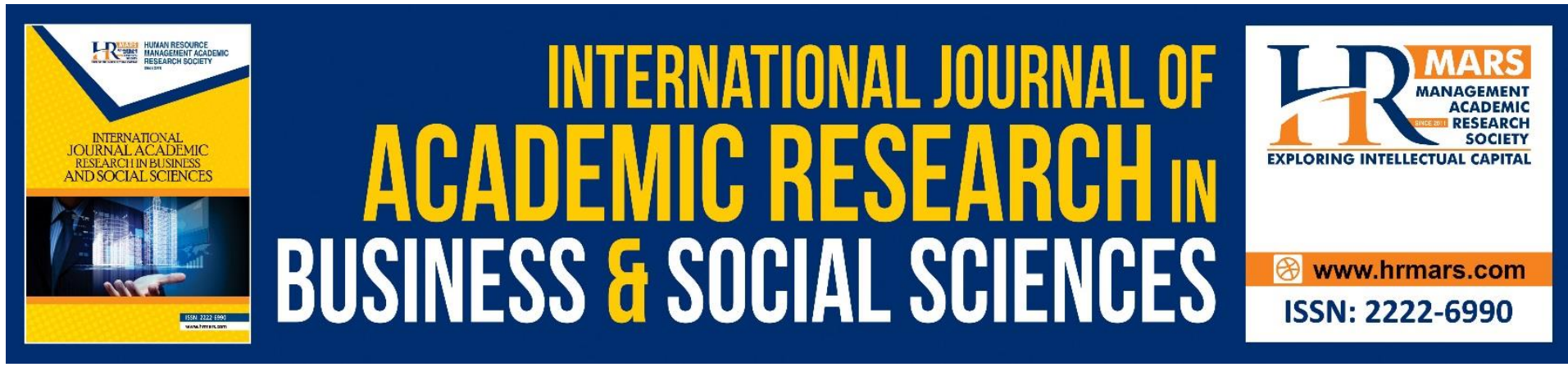

\title{
Entrepreneurial Leadership in the Micro and Small Enterprises (MSES) Research Context: A Literature Review
}

\author{
${ }^{1}$ Suraiya Ishak, ${ }^{2} \mathrm{Ahmad}$ Raflis Che Omar, ${ }^{3} \mathrm{Azima}$ Abd. Manaf \\ ${ }^{1,3}$ Centre for Social, Environment \& Development Studies, Faculty of Social Science \& \\ Humanities Universiti Kebangsaan Malaysia 43650 Bangi Selangor, Malaysia, ${ }^{2}$ Centre of \\ Value Creation \& Human Well Being, Faculty of Economics \& Management Universiti \\ Kebangsaan Malaysia 43650 Bangi Selangor, Malaysia \\ Email: suraiya@ukm.edu.my
}

\begin{abstract}
The review aims to provide an understanding of the recent concepts in leadership for managing turbulent and dynamic business contexts. The objective of this paper is to disseminate a rigorous understanding of the Entrepreneurial Leadership (EL) concept through a narrative literature review covering definitions, dimensions and trends of recent studies on the topic. The effort expected to encourage more studies on EL and organizational performance within the specific context of the Micro and Small Enterprises (MSEs) in developing countries. The discussion uses the narrative or traditional type of literature review. Based on the review, EL is a stimulative type of leadership that inspires towards an entrepreneurial orientation behaviours throughout an entire organization. Entrepreneurial leaders are individuals who, through an understanding of themselves and the contexts in which they work, act on and shape opportunities that create value for their organizations, their stakeholders and the wider society. The EL field is still evolving and there are many areas for future researchers to engage in studying the effects of EL. Currently, research trends on EL can be segregated into two stages. The current trend is now focusing on the $2^{\text {nd }}$ stage involving empirical studies on the process model related to the effects of EL on small business performance. This study contributes to the existing literature on Entrepreneurial Leadership $(E L)$ that is essential to sustain and re-develop micro and small businesses.
\end{abstract}

Keywords: Entrepreneurial Leadership, Micro and Small Enterprises, Leadership, Narrative Review, Entrepreneurship

\section{Introduction}

Micro and small medium enterprises (MSMEs) activities are essential to the economic transformation process among developing nations (Sawaean \& Ali 2020; and Tsetim, Asenge \& Adudu 2020). Senthilkumar (2020); Tsetim et al. (2020) and Eniola \& Entebang (2015) states that MSEs play significant roles in the global economy through contribution to output, employment and income. As such, the role of MSEs is significant in the case of developing countries pursuing ideal income distribution, poverty reduction and an economic 
development agenda. Nevertheless, these entities are often confronted with intense competitive pressures from the environment. Therefore, MSEs must enhance their competitive abilities in critical aspects to ensure its continual growth and performance.

Numerous studies have been devoted to examining the antecedents of small firm performance such as government policies; entrepreneurs' competency and characteristics; and technological usage (Eniola \& Entebang 2015; Radzi, Mohd Nor \& Ali 2017; Heslina, Payangan, Taba \& Pabo 2016). On top of that, the characteristics and competencies of business leaders (owners) have been found to be essential to small firms' performance (Eniola \& Entebeng 2015; Radzi et al. 2017; and Heslina et al. 2016). The finding indirectly reflects that MSE owners (who are the main leaders for their business) must possess entrepreneurial characteristic and competencies. Moreover, numerous studies have suggested that leadership is a critical factor in shaping and promoting organizational performance (Arif \& Akram 2018; Jing 2017; and Madanchian, Hussein, Noordin \& Taheerdoost 2016). These reiterate the critical role of leadership in achieving superior performance within the micro and small business contexts.

Even though there have been many studies which have explored leadership role in driving business performance, there is relatively limited understanding of variations in leadership styles that effectively augment business performance and growth. Typical leadership styles in previous studies on business performance are charismatic, transformational leadership and transactional leadership (Paudel 2019; Arif \& Akram 2018; Jing 2017; Leitch \& Volery 2017; Madanchian et al. 2016; and Jacobs \& Mafini 2019). Nonetheless, this study aims to add values to the knowledge of leadership within the MSEs context by analyzing Entrepreneurial Leadership (EL). The main purpose is to provide insight that would enable better understanding about EL and to promote more empirical studies on EL.

The current review is presented in the form of a narrative or traditional type of review. Based on Ferrari (2015), there are two types of literature reviews, which are (1) systematic; and (2) non-systematic or narrative. A narrative or traditional literature review is a comprehensive, critical and objective analysis of the current knowledge on a topic. They are an essential part of the research process and help to establish a theoretical framework. The aims of the narrative review are identifying and summarizing what has been published previously, avoiding duplication, and seeking new study areas which not yet addressed. Unlike a systematic review, there are no acknowledged guidelines for narrative reviews, nor a consensus on the structure of narrative review. Thus, the methods section is not mandatory for the narrative review, although it may be able to improve the clarity of a message (Ferrari 2015).

\section{The Theoretical Domain of Entrepreneurial Leadership (EI) in Mses Context}

In the last two decades, EL has become a hot topic and attracted scholars' attention both in the entrepreneurship and leadership domains (Cai Li et al. 2020; Bagheri \& Harrison 2020; Harrison et al. 2019; Leitch \& Volery 2017; Senthilkumar 2020). Harrison et al. (2019) recently presented a systematic literature review (SLR) on EL studies which reiterates EL as an important factor that enhances organizational performance in a turbulent and competitive business environment. Based on Van Zyl \& Mathur-Helm (2007), the influence of EL on the 
choice of the appropriate blend of market orientation and relationship marketing orientation of an enterprise, leads to different levels of firm performance.

The role of EL is especially important in the MSEs context since the entire business relies solely on the owner. Thus, the business owner needs to envisage the entire firms' growth and sustainable performance through effective behaviors and abilities. Al Mamun et al. (2018) suggest that micro and small firms performance rely heavily on entrepreneurial characteristics and competencies such as leadership capabilities, managerial and networking skills, technological capabilities and the entrepreneurs' education level. As such, EL is pivotal in determining the success of the micro and small business ventures. Small and micro businesses, including start-ups, are usually closely tied to the owners as most are ownermanaged, with a flat hierarchy and direct access to the owner-managers. There is no clear separation between the leadership and managerial roles in the micro and small business context (Leitch \& Volery, 2017). In such a context, the top person need to exercise a strong leadership style to direct and to provide strategic direction for the entire organization or to enact certain trends/needs.

The need is far more critical within the context of a dynamic and turbulent environment. In a dynamic and turbulent business environment, it is necessary to quickly adapt the organizational structures and processes as the business pivots in the search of a better business model or growth. This calls for leadership behavior able to address numerous paradoxes and tensions. As a result, entrepreneurial leadership serves as a distinctive concept, which take into consideration the specific implementation of leadership in the new and small firms rather than large established organizations; as well as the high-velocity of competition environment. Tsetim et al. (2020) has recognized EL as one of the recent solutions to the challenges associated with current competitive and dynamic global business environment.

In the context of post COVID-19 pandemic, EL has served as an essential strategic asset that potentially create value amid massive turbulence and changing business norms. Due to the pandemic spread and the deterring actions to mitigate virus spread such as Movement Control Orders (MCOs), most micro and small businesses are dragged into the most dangerous phase in their business cycle (Castro \& Zermeno 2020; Fairlie 2020; Omar, Ishak \& Jusoh 2020). Many businesses have been seized due to inability to absorb the operating and capital cost; while other businesses have become obsolete due to the unexpected anomalies that rampantly changed the ordinary business environment (Omar et al. 2020; Fairlie 2020). Overall, micro and small businesses are bearing the brunt of COVID-19 related economic fallout. Business resilience as the output of an effective entrepreneurial skills would allow some companies to adapt and grow stronger in the face of this great crisis (Castro \& Zermeno, 2020). This demands a strong leadership style that able to enact new perspectives to the entire organization as well as to the market and society.

\section{Theoretical Basis}

EL is a concept derived from the two theoretical backgrounds of leadership and entrepreneurship. 


\section{Entrepreneurship}

Within the context of entrepreneurial economy, the role of the government is restricted to facilitating and stimulating entrepreneurial activities among the people. The entrepreneurial economy emphasizes the role of value creation activities that based on innovative, proactive and acceptance of calculated risks for gaining long term economic growth (Ndofirepi, 2020; Block, Fisch \& Van Praag, 2016; Filser et al., 2019). Hence, entrepreneurs are acknowledged as the main agent that drive country towards development and modernisation (Jaimovich, 2010). The entrepreneurial economy has features such as the following (Audretsch \& Thurik, 2000):

(a) Emphasis on changes and large or radical scales improvement;

(b) Specialization as a mean to achieve competitiveness;

(c) Attaining full employment condition without lowering wages. Basically, full employment can be reach with high wage rates because entrepreneurial economy emphasizes on the creation of products/services based on high knowledge. This would justify the premium price of products/services.

(d) Government policies limited to creating an environment that supports and facilitates economic actors to implement more innovation and growth.

As far as entrepreneurship is concerned, business ventures require extraordinary leaders. A leader must be able to set visions and encourage all members towards achieving the inspired visions and configure the accurate structures as well as resources for obtaining the visions. The leadership must demonstrate the abilities to influence members and to encourage them towards the right success path especially during a turbulent period. Therefore, a specific leadership style must be integrated to the notion of entrepreneurship concept.

\section{Leadership}

The relevant aspects of leadership for managing turbulent and dynamic environment are transformational, team-oriented and value-based leadership. Transformational leadership includes visionary, inspiring, risk-takers, and thoughtful thinkers. Although transformational leaders have the charismatic appeal, they do not rely merely on the charisma alone because it is insufficient for changing the way the organization operates. Transformational leaders must exhibit four factors to create major changes, namely inspirational motivation, intellectual stimulation, idealized influence and individualized consideration (Khan, Hawaz \& Khan, 2016). Team-oriented leadership or people-oriented leadership contradicts with the task-oriented leadership style. Team-oriented leadership involves developing and supporting people within the team. Team-oriented leaders are concerned with how their decision affect others and weights their decisions heavily against any final action (Bell, 2019). All members feel ownership of the decision taken and are committed in carrying out the decision. This type of leadership requires a high level of communication with the staff members. Value-based leadership emphasizes the values of the organization to drive performance, especially in times of change. An organization's values should be the bedrock of why the company exists, how it makes decisions and its true purpose. It must be authentic and relatively specific so it can resonate with the team (Gleeson, 2017). Values-based leaders effectively engage, motivate and develop their followers, establishing a culture that enables sustainable change, and inevitably results for an effective execution, innovation and outstanding performance (Taylor, 2011). Based on these three types of leadership (i.e. transformational, people oriented and value-based leadership), a few points can be related to the discussion of entrepreneurship: 
(a) The aforementioned theories are recognized as the type of leadership that have the highest influence on followers (members), in which the followers are "naturally" attracted to follow the leaders due to their highest recognition, belief and respect (all internally driven) towards the leaders.

(b) The leaders execute the "management by example" or becomes the role model in providing directions and to make followers to understand the situation and current expectation. They do not merely give instructions on what to do or to achieve but to make people (followers) understand the need to achieve the objective in the first place by proving examples or accomplishing the tasks (expectations) first.

(c) Leaders emphasize empowering people, respect and believe in followers' ability and to provide clear directions and not restricting according to their perspectives on how things should be managed.

(d) The theories represent the current mode of leadership that emphasize the innovation culture and beyond ordinary practices.

Thus, the aforementioned leadership styles fit with the role of entrepreneurs as the innovator and catalyst of change in the market. These types of leaderships are able to deliver growth and survival for the micro and small business entities.

The intersection point of the entrepreneurship and leadership theoretical domains make ways to the emergent of EL concept that blends the need for leadership most suitable to the context of MSEs in a high uncertainty, turbulent and dynamic environment. Figure 1 provides an illustration of the theoretical discussion.

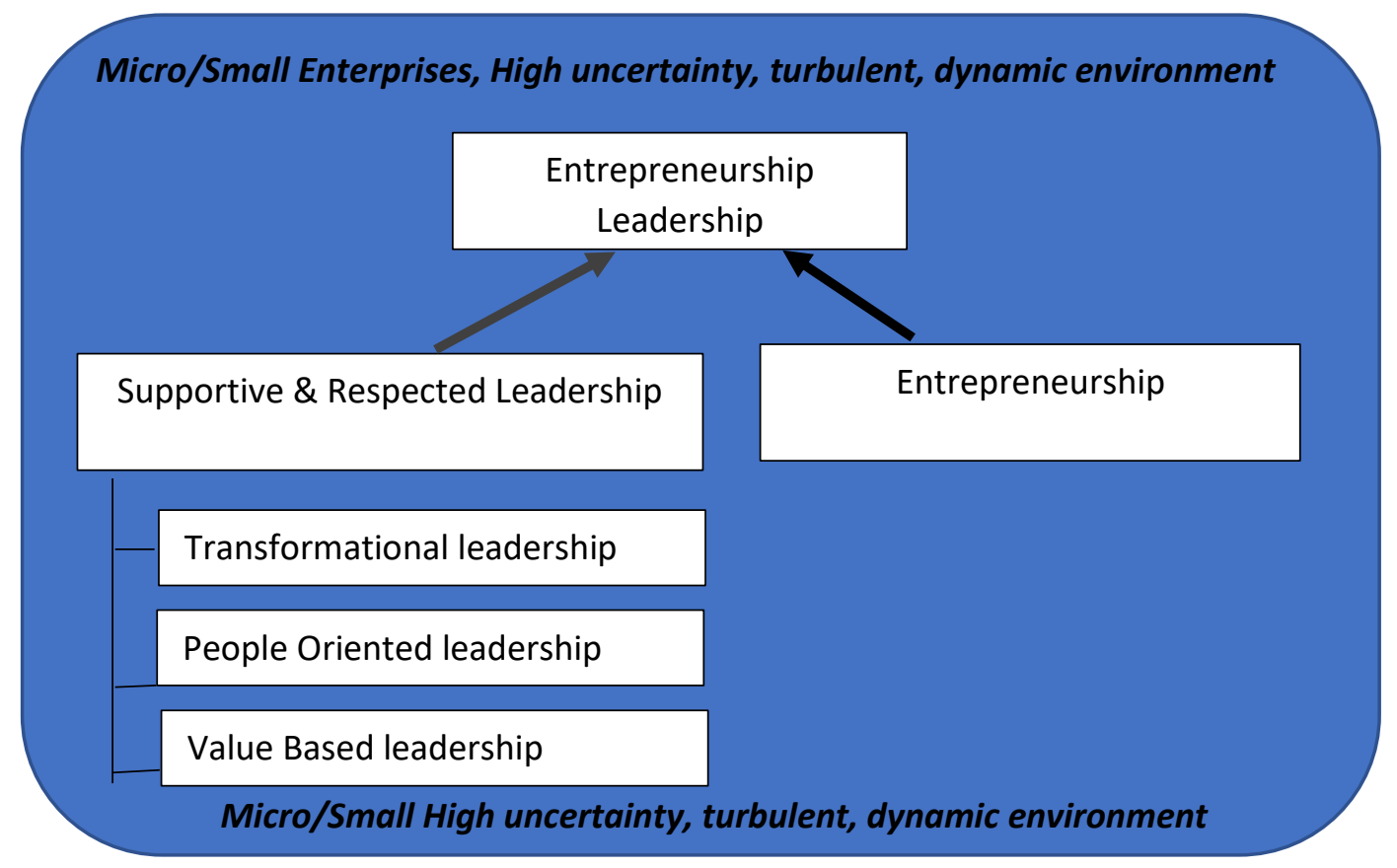

Figure 1 Theoretical Basis of El Within Mses Context

Based on Castro \& Zermeno (2020) study, small business resilience is determined by factors such as attitudes adopted toward crisis, the characteristics of the business and entrepreneurs, the relationships with institutions, human and social capital, and strategic management. These factors reflect that entrepreneurial skill is necessary to remain resilience in crisis. Entrepreneurial skills give a person an ability to develop new company and to promote social 
development. Based on previous findings, resilience factors can be combined under the EL concept as depicted in Figure 1. The way a business adapts to its changing environment is closely linked to the ability of its leaders to formulate effective strategies to adapt with the crisis. Leaders with EL capability are able to create positive attitude towards crisis and to create new atmosphere which stimulate the members to embrace positive and creative reaction to the changing business norms and environment. Leaders with $\mathrm{EL}$ are also able to strategically re-position their business to fit the new environment as well to encourage employees to embrace and execute new visions creatively. Hence, EL is an important skill that must be nurtured among future entrepreneurs.

Based on Tsetim et al.'s (2020) findings, the managers/owners of SMEs must embrace EL especially in terms of how to create and communicate vision effectively as these elements found to correlates positively with SMEs performance. Another study by Radzi et al. (2017) also found that among the significant internal based assets that have significant positive relationship with business success is the entrepreneur competency. Thus, it is relevant to acknowledge business owners (particularly for the micro and small business context) as the major gatekeeper of the business. The business owners able to determine the optimization of the firm internal resources to achieve business success (Radzi et al., 2017; and Heslina et al., 2016). Thus, the EL concept represent the overall entrepreneur competency and characteristics that determine small business success.

The next sub-topic describes the EL concept through the definition and dimensions of the concept.

\section{Definition of Entrepreneurial Leadership (EL)}

Currently, EL field is still in infancy. Therefore, the theory development is largely concentrated at the embryonic phase which requires massive efforts prior to stabilization of the field (Leitch $\&$ Volery, 2017). As an evolving field, there are some weaknesses in certain fundamental aspects, such as definitional clarity and absence of measurement tools for assessing EL characteristics. What is entrepreneurial leadership (EL)?

Entrepreneurial leaders are able to recognize opportunities, create visions and mobilizing key resources holders to enact vision and creating values. Entrepreneurial leaders are individuals who, through an understanding of themselves and the contexts in which they work, act on and shape opportunities that create value for their organizations, stakeholders and the wider society (Karim et al., 2019). Entrepreneurial leaders are driven by the desire to create the social, environmental and economic opportunities simultaneously. They are not disrupted by lack of resources or high level of uncertainty. Meanwhile, Tsetim et al. (2020) defines EL as affecting and directing the performance of employees toward the achievement of organizational objectives by recognizing and exploiting of entrepreneurial opportunities.

Entrepreneurial leaders play a role in restoring and stimulating entrepreneurial behaviors within the organization's atmosphere and among its members. The entire organization are driven to behave as an "entrepreneur" by embracing entrepreneurs values such as innovative, proactive, risk taking, authoritative and high self-confident (Cai Li et al., 2020). Entrepreneurial leaders induce their group members to discard conventional ways of performing task and direct their energy towards executing innovative and entrepreneurial actions. Entrepreneurial leaders re-create their members' perception about their 
competencies by involving them in developing new and innovative idea and build confidence to implement the idea (Cai Li et al., 2020). ELs encourage the entire organization to adopt processes that reinforce the culture of organizational innovation through discovering and capitalizing of opportunities to improve organizational performance, solving problems by creative methods and utilizing organization resources effective and efficiently (Sawaean \& Ali, 2020). Entrepreneurial leadership relates positively to business performance because it drives innovation and development which based on the customer and competitors situation (Van Zyl \& Mathur-Helm, 2007). Therefore, it is relevant to examine the skills and characteristics of owners, which best represented by EL concept, since most micro and small business owners are also the main leader of their businesses.

Gupta et al. (2004) made a significant contribution by pioneering the EL concept by blending existing concepts of entrepreneurship by Shumpeter, entrepreneurial orientation by Covin \& Slavin, and entrepreneurial management by Stevenson, with leadership. Gupta et al. (2004) define EL as leadership that creates visionary scenarios used to assemble and mobilize the supporting cast of participants who become committed to the vision of discovery and exploitation in strategic value creation. The EL concept represents leadership style across three main dimensions, consisting of innovation, proactiveness and risk taking (Gupta, 2004). Innovation means the leader able to reinforce creativity among team member in making effective change and pioneering novel product (services) to create competitive advantage for the organization. Meanwhile, proactiveness refers to motivating team members to compete aggressively and continually with other organizations. The risk-taking dimension refer to willingness to face uncertainty and take responsibility.

Based on Al Mamun et al. (2018), EL is a concept located at the intersection of leadership and entrepreneurship. Leadership is the process of influencing and getting others to pursue certain objective/purpose; while entrepreneurship reflects entrepreneurs and the intersection of entrepreneurs and their surrounding opportunities. Thus, it represents the intangible resources held by the organization that relate to its human resource. Entrepreneurs play roles as the founder and dominant pillar for business progression. Gupta et al. (2004) proposed that the pragmatic EL definition rest upon two important pillars. First, the entrepreneurial leaders are expected to bring into reality an environment of possible opportunities to reconstruct the existing situation (scenario enactment). Enactment refer to a process of forming new reality and not about analysis of existing reality. They need to envisage new or alternative perspective or views able to change current situation. Secondly, they must be able to persuade followers and stakeholders on the possibility of achieving the target scenario by recruiting additional cast and adopting appropriate resources to execute the transformation (cast enactment).

In an increasingly dynamic and competitive business environment, traditional leadership has become ineffective and unfit to face current market turbulence (Paudel 2019; Tsetim et al. 2020). Thus, Entrepreneurial Leadership is a necessary form of leadership in an unpredictable and competitively volatile dynamic economy and rapidly changing business environment. The leader observes him/herself as an entrepreneur when managing their own business (Sandybayez, 2019). Thus, it refers to leadership with high level of self-confidence in conjunction with entrepreneurs behaviour in pursuing an organization's vision and plans. They take responsibility to create condition, in which it organically creates its order of matters 
and reacts creatively to changes in the external environment, rather being managed by the environment forces. Within the context of environmental dynamism, EL is essential to driving organizational innovation (OI) and creativity, contributing to higher business performance (BP) (Paudel, 2019). Hence, EL is distinct from other forms of leadership and necessary for a turbulent and competitive situation and associated with superior performance and survival.

\section{Dimensions of EL}

Entrepreneurial leadership is influenced by a number of variables (Senthilkumar, 2020). Gupta et al., (2004) has pioneered the effort to establish the EL concept and dimensions from the universal theoretical basis of leadership theories that most relevant to entrepreneurship (i.e. neocharismatic/transformational leadership, team-oriented and value based leadership) and the entrepreneurship literature. Gupta et al.'s (2004) dimensions of EL consist of foresight, encouraging, positive, confidence builder, decisive, effective bargainer, informed and team builder. On top of that, entrepreneur leadership possess additional characteristics such as ambitious, enthusiastic, performance oriented, improvement oriented, inspirational, visionary, intellectually stimulating, intuitive, integrator and diplomatic.

Meanwhile, Sawaean \& Ali (2020) proposed four EL dimensions, consisting of visionary, opportunity seeking, proactive and risk-taking propensity. Contrary, Bagheri \& Harrison (2020) have suggested a list of 40 items that can be used to explore EL from the perspective of followers. Specifically, Bagheri \& Harrison (2020) suggest a range of relevant dimensions consist of framing challenges, absorbing uncertainty, underwriting, building commitment, defining gravity, opportunity identification and exploitation, orientation towards learning, and the creative collective of self-efficacy. By such dimensions, Bagheri \& Harrison (2020) included the skills and competencies of entrepreneurial leaders and their specific behaviour in performing tasks and roles, on a multidimensional constructs of EL measure. Another study by Harrison et al. (2019) identified relevant attributes such as vision, creativity, effective communication and risk taking from the SLR. Meanwhile, Al Mamun et al. (2018) focused on a few constructs that most relevant within the context of its studied context (microentrepreneurs from low-income households), which are responsibility, accountability, analytical thinking and emotional intelligence. Sandybayez (2019) describes EL as a combination of various personal qualities and characters. Thus, entrepreneurial skills and specific characteristics are central to the measurement of EL (Sandybayez 2019). Specifically, the constructs consist of creativity, passion, vision and risk taking. Paudel (2019) used the measurement of five constructs to measure the EL concept, namely framing the challenge, absorbing uncertainty, underwriting, building commitment and defining gravity.

Senthilkumar (2020) has used the leading variables of entrepreneurial leadership which are categorized into four factors such as strategic, communicative, personal and motivational. The Strategic dimension is comprised of variables such as the vision of the entrepreneurs, predictability, holistic view, flexibility in decisions, willing to take risk, opportunism, innovative and dealing with threats. Next, the Communication dimension is measured through persuasion, empathy, conflict management, openness, listening, inspiring followers, ensuring perfect communication system and recognizing followers. The Motivation dimension of the entrepreneurial leadership includes variables such as ability to influence followers, enjoying influencing followers, motivation in getting success in the business, motivation to perform hard works, consistent and persistence in efforts, motivation by 
appropriate compensations, transferring and maintaining the positive environment and acknowledging and appreciating the efforts of the followers. Finally, the Personal factor includes variables such as emotional intelligence, creativity, hyperactivity, modesty, mapping the competences, ingenuous, discipline and courage. Thus, Senthikumar (2020) included task and personal based factors to operationalize the EL concept.

Tsetim et al. (2020) focuses on four dimensions, consisting of miner, explorer, accelerator and integrator behaviours. Entrepreneurial leaders who are miners target the inwards approach, searching for avenues to see and expose hidden treasures that often stay untapped in the company's internal operations and developments. Entrepreneur's miner behaviour encompasses a leader's ability to analyse the work load and productivity of employees, as well as supporting them to overcome challenges on their own capacity. Accelerator behaviour includes stimulating employees for creative ideas, triggering them to increase productivity using innovative methods and creating a empowering environment for them to try new strategies. Explorer behaviour represents the entrepreneurial leaders' actions towards discovering hidden opportunities for the business growth, developing creative policies for the firm's performance improvement and foreseeing an innovative future for the firm. Explorer behaviour is a leader's ability to motivate staff to imagine for new and innovative approaches to develop the firms. Finally, Integrator behaviour is exhibited when the organizational vision is conveyed to the staff, motivating them to embark an entrepreneurial thinking as well as making finances available for realizing the innovative ideas. Tsetim et al. (2020) argues that if a leader covers the four dimensions, he or she would cover the general entrepreneurial leadership behaviour dimensions.

Despite the importance role in navigating business performance in turbulent environment, the identified attributes of EL remain ambiguous within a specific context (Harrison et al. 2019). Thus, more studies on EL are welcomed in specific contexts such as the developing economies. This shows that to certain extent the unique context of the local environment may influence the nature and disposition of the EL concept. Furthermore, according to Bagheri \& Harrison (2020), the definition of EL and theory have remained underdeveloped due to a few reasons. First, there is no consensus among scholars on the definition of the notion. Second, there is still no consensus among scholars on the dimensionality of the constructs. Some researchers assume it to be multidimensional, whereas others have treated it as unidimensional constructs. Additionally, Bagheri \& Harrison (2020) reiterates EL as a concept that is influenced by context, thus the contextual element must be considers when developing an EL measures. The next section elaborates the research trend of EL to form a general understanding on current EL studies and to provide insights into the upcoming EL research agenda.

\section{El Research Trend}

EL is a new field that requires extensive works(Leitch \& Volery, 2017). Based on Leitch \& Volery (2017), the evolution of EL began in the 1990s and until now the progress can be traced in two stages. In the first stage, the studies on EL began to shift from previous focus of studying the personal characteristics and traits towards examining the roles and behaviors defined by interactions within a specific context. The first stage evolution depicts the inclusion of more dynamic interactions, which occur throughout the execution of tasks or functions in real environment. The second stage represents a shift from static, descriptive or diagnostic 
analyses, based on the psychological approach, to a dynamic view of EL from the process perspective. The studies within the second stage group examine process model that explicitly considers various inter-relationship among variables that involve EL in a direct, mediating or moderating framework models. Although studies on EL have thrived within the identified evolution stages, there are gaps which remain. One of the necessary area is to develop insight that is more theoretical and to use rigorous empirical methods that considers the context of MSEs. This would encapsulate unique issues prevail within the context of MSEs that closely relate to the role of EL. In addition, future studies are urged to enhance the understanding of EL within various countries and regions because the existing studies have largely dominated by the Anglo-American framework model (Leitch \& Volery 2017).

The focus of recent research trend on EL can be understood from the review on EL studies shown in Table 1. 
INTERNATIONAL JOURNAL OF ACADEMIC RESEARCH IN BUSINESS AND SOCIAL SCIENCES

Vol. 11, No. 5, 2021, E-ISSN: 2222-6990 @ 2021 HRMARS

TABLE 1: REVIEW ON RECENT STUDIES ON ENTREPRNEURIAL LEADERSHIP

\begin{tabular}{|c|c|c|c|c|c|c|c|c|}
\hline No & Authors & EL* & $\begin{array}{c}\text { Independent } \\
\text { variable }\end{array}$ & $\begin{array}{c}\text { Moderating } \\
\text { variable }\end{array}$ & $\begin{array}{c}\text { Mediating } \\
\text { variable }\end{array}$ & $\begin{array}{l}\text { Dependent } \\
\text { variable }\end{array}$ & $\begin{array}{c}\text { Result (role } \\
\text { of EL) }\end{array}$ & $\begin{array}{l}\text { Context of } \\
\text { study }\end{array}$ \\
\hline 1. & $\begin{array}{l}\text { Cai Li et al. } \\
(2020)\end{array}$ & IV & - & $\begin{array}{c}\text { Entrepreneurial } \\
\text { self-efficacy }\end{array}$ & $\begin{array}{c}\text { Firms' } \\
\text { innovative } \\
\text { environment }\end{array}$ & $\begin{array}{c}\text { Employees' } \\
\text { innovative } \\
\text { behavior }\end{array}$ & & $\begin{array}{l}\text { Micro } \\
\text { business }\end{array}$ \\
\hline 2. & $\begin{array}{c}\text { Ximenes et al. } \\
\text { (2019) }\end{array}$ & MV & $\begin{array}{l}\text { High } \\
\text { performance } \\
\text { work } \\
\text { systems; } \\
\text { Employee } \\
\text { creativity }\end{array}$ & - & - & $\begin{array}{c}\text { Employee } \\
\text { performance }\end{array}$ & Significant & $\begin{array}{c}\text { Co- } \\
\text { operatives } \\
\text { (Timor } \\
\text { Leste) }\end{array}$ \\
\hline 3. & $\begin{array}{c}\text { Yang et al. } \\
\text { (2019) }\end{array}$ & IV & - & Person-job fit & $\begin{array}{c}\text { Affective } \\
\text { commitment }\end{array}$ & $\begin{array}{c}\text { Employees } \\
\text { turnover } \\
\text { intention }\end{array}$ & Significant & $\begin{array}{c}\text { Newly } \\
\text { established } \\
\text { firms (less } \\
\text { than } 5 \\
\text { years) } \\
\text { (China) }\end{array}$ \\
\hline 4. & $\begin{array}{c}\text { Van Zyl \& } \\
\text { Mathur-Helm } \\
\text { (2007) }\end{array}$ & IV & - & - & $\begin{array}{c}\text { Firms } \\
\text { strategic } \\
\text { orientations. }\end{array}$ & $\begin{array}{c}\text { Enterprises } \\
\text { performance }\end{array}$ & & $\begin{array}{c}\text { Small } \\
\text { tourism } \\
\text { firms } \\
\text { (South } \\
\text { Africa) }\end{array}$ \\
\hline 5. & $\begin{array}{c}\text { Sawaean \& Ali } \\
(2020)\end{array}$ & IV & - & - & $\begin{array}{l}\text { Innovation } \\
\text { capacity }\end{array}$ & $\begin{array}{c}\text { Learning } \\
\text { orientation; } \\
\text { Performance }\end{array}$ & Significant & $\begin{array}{c}\text { Small } \\
\text { medium } \\
\text { enterprises } \\
\text { (Kuwait) }\end{array}$ \\
\hline 6. & $\begin{array}{l}\text { Al Mamun et } \\
\text { al. (2018) }\end{array}$ & IV & - & - & $\begin{array}{l}\text { - Enterprise } \\
\text { performance }\end{array}$ & $\begin{array}{c}\text { Enterprise } \\
\text { performance } \\
\text { Enterprise } \\
\text { sustainability }\end{array}$ & Significant & $\begin{array}{c}\text { Micro- } \\
\text { enterprise } \\
\text { (Malaysia) }\end{array}$ \\
\hline 7. & $\begin{array}{c}\text { Sandybayev } \\
(2019)\end{array}$ & IV & - & - & - & $\begin{array}{l}\text { Organization } \\
\text { performance }\end{array}$ & Significant & SMEs (UAE) \\
\hline 8. & Paudel (2019) & IV & - & $\begin{array}{c}\text { Environmental } \\
\text { Dynamism }\end{array}$ & $\begin{array}{l}\text { Organization } \\
\text { Innovation }\end{array}$ & $\begin{array}{c}\text { Business } \\
\text { performance }\end{array}$ & $\begin{array}{l}\text { Significant } \\
\text { positive }\end{array}$ & $\begin{array}{l}\text { SMEs in } \\
\text { South Asian } \\
\text { (Nepal) }\end{array}$ \\
\hline
\end{tabular}




\begin{tabular}{|c|c|c|c|c|c|c|c|c|}
\hline 9. & $\begin{array}{c}\text { Senthilkumar } \\
\text { (2020) }\end{array}$ & IV & - & - & - & $\begin{array}{c}\text { Business } \\
\text { Performance }\end{array}$ & $\begin{array}{l}\text { Significant } \\
\text { positive }\end{array}$ & $\begin{array}{l}\text { Micro and } \\
\text { Small } \\
\text { Enterprises } \\
\text { (MSE) } \\
\text { (Ethiopia) }\end{array}$ \\
\hline 10 & $\begin{array}{c}\text { Tsetim et al. } \\
\text { (2020) }\end{array}$ & IV & - & - & - & Performance & $\begin{array}{l}\text { Significant } \\
\text { positive }\end{array}$ & $\begin{array}{c}\text { SMEs } \\
\text { (Nigeria) }\end{array}$ \\
\hline
\end{tabular}

Note* : Independent Variable (IV); Moderating Variable (MV)

As shown in Table 1, those studies fall within the scope of the second evolution stage, in which the studies have examined the process model that explicitly considers inter-relationship among the variables. As seen in Table 1, is EL largely studied as an independent variable associated with various scopes of performance process. A few studies focus the relationship of EL on employees' performance such as Cai Li, Makhdoom \& Asim (2020); and Yang, Pu \& Guan (2019). Others have examined the EL relationship with an organization's level of performance, such as the enterprise performance, enterprise sustainability, and business performance (Van Zyl \& Mathur-Helm 2007; Sawaen \& Ali 2020; Al Mamun et al. 2018; Sandybayez 2019; Paudel 2019; Senthilkumar 2020; Tsetim et al. 2020). On top of that, Yang et al. (2019) treat EL as a moderating variable, which intervene the relationship between high performance work systems, employee creativity and employee performance. In general, EL has been found to be significant within relationships, as shown in Table 1.

As shown in Table 1, most recent studies have involved the micro, small and medium enterprises outside the Western context. The emerging trend shed positive development on EL research trends parallel with Paudel (2019) that most entrepreneurship concepts were comprehended within the understanding of the Western context. Thus, the relevance to Eastern and developing countries is relatively arguable (Paudel, 2019). Due to distinct cultures, dynamic of environment and existence of different challenges in the Asian countries, the variables measured in Western context and its relationship with performance might be different from the non-Western context (Paudel, 2019). Moreover, the validity issues for the variables measures, which developed in Western context remain doubtful for replication in a different cultural contexts. Therefore, emerging studies on entrepreneurship and business performance from various Asian and micro and small contexts have emerged as the recent research focus on EL studies.

Based on Table 1, the studies on EL have involved two levels of performance issues that comprise of the individual (employee) and organizational performance. Cai Li et al. (2020); Ximene et al. (2019); Yang et al. (2019) examine the relationship between EL and various indicators of employee performance. For instance, Cai Li et al. (2020) studied the relationship between entrepreneurial leadership (IV) and employees' innovative behaviour (DV). The study explores the effect of the relationship through the moderating effect of entrepreneurial self-efficacy and the mediating effect of firms' innovative environment. The unit of analysis emphasize by this study is the employee working behaviour. Ximenes et al. (2019) explored the role of EL as the moderating variable that potentially influence the relationship between high performance work systems, employee creativity and employees performance. In addition, Ximenes et al. (2019) evaluated the moderating effect of EL on employee 
performance within the co-operatives context. The results show that EL is a significant moderator that influence relationship between high performance work system, employee creativity and employee performance. The unit of analysis emphasize by this study is the employee performance in the cooperative settings. Meanwhile, Yang et al. (2019) explores EL and turnover intention of employees by examining the mediating effect of affective commitment and the moderating effect of person-job fit in start-ups. The results indicate that $E L$ is an effective style of leadership and plays a crucial role in the development of a business venture.

At the same time, a few studies have examined the performance issue at the organizational level. For instance, Van Zyl \& Mathur-Helm (2007) investigates EL effect on firms strategic orientations (i.e. market orientation and relationship marketing). The study examined the effect of EL on the performance of the tourism based small enterprises through the mediating effect of the strategic orientations. The unit of analysis emphasize by this study is the small business involved in tourism which refer to the organization level of performance issue. Similarly, Sawaean \& Ali (2020) looked into the relationship of EL and learning orientation and SMEs organizational performance through the mediating variable of innovation capacity, which is also classified at the organizational level of analysis. The study found significant relationship between EL and learning orientation on SMEs performance. Besides that, innovation capacity found to be a significant mediator for the relationships with SMEs performance. Sandybayez (2019) found a significant positive relationship between EL and SMEs organizational performance. Thus, EL is a robust predictor of organizational performance and it justifies the need for MSEs to embrace EL to stay competitive in the market. Due to the significance of EL in determining business performance, more studies are needed to understand it in various contexts, especially among developing and Asian context as well other specific characteristics that differs across studied population. The effort would enhance additional values to the body of knowledge related to EL and business performance.

\section{Discussion}

The improvement of the vulnerable groups' socioeconomic wellbeing can be achieved sustainably through effective entrepreneurial and business activities. Moreover, the Sustainable Development Goal (SDG) acknowledge Entrepreneurship as an effective platform to improve the people wellbeing and to reduce all forms of poverty across all group of people. Thus, the situation gives signal that it is utmost important to ensure the micro and small businesses are able to contribute to the resilient and empowerment of the nation economic status. As far as the development is concerned, it is necessary to develop internal and domestic economic players as the major pillar that support the country's economic resilient. MSEs must not merely exist for a short period of time, but must be capable to grow and prosper in the long run.

Entrepreneurs play a significant role in reforming production patterns through the exploitation of existing creation or by adopting new technology which have not been used previously. From the creative destruction activities, the entrepreneurs are able to produce new commodities or new method for producing existing products. The entrepreneurial activities lead towards new offerings or new market by re-configuring existing industries and economies. Eventually, the economic development and prosperity derived from the innovation activities run by the entrepreneurs. As far market is concerned, business does not 
operate in isolation context. Moreover, businesses operate within an uncertain environment. The COVID-19 pandemic is one of the recent threat faced by business players in all sectors and scales.

Within this unexpected situation, the role of leadership has become critical to the succession, growth and survival of the business. As a result, the role of leader is pivotal to determine the future of the business ventures. Most micro and small businesses have a close connection to its owners, because most of the Malaysian micro and small business ventures are established as sole proprietorships and partnerships. In addition, there are many informal micro businesses at the start-up phase managed entirely by owners (entrepreneurs). Thus, the inseparable of the owners and management become a reason that justifies leadership ability in determining the business performance. Within this context, the business future depends heavily on leadership capability.

Entrepreneurial Leadership (EL) is an encouraging type of leadership that inspires towards entrepreneurial orientation behaviors throughout the entire organization. As far as leadership is concerned, EL blends the effective traits and features of the previous leadership style such as transformational leadership, team-oriented and value-based leadership. EL is necessary for MSEs to have EL to ensure its growth and sustainability. Businesses led by EL have greater growth potential and remain viable within a changing environment. Based on the narrative reviews, we able to point few implications for future research within the scope of the EL research trends agenda:

(a) It is necessary to examine the EL level of the MSEs owners-leaders across various groups and contexts. Understanding the level of EL within a specific context sheds practical implications that can be used to enhance business performance through the implementation of effective leadership. Thus, entrepreneurial aids or training schemes must be designed in line with the level of EL within a specific context, and some degree of EL must be nurtured among the micro and small business leaders prior to any business aids. As such, a robust understanding on EL allow future researchers to measure the concept and to assist policy makers (practitioners) to formulate effective entrepreneurial programmes aim at developing EL among the local MSEs leaders. Eventually, the effort lead towards continual growth and superior performance of the MSEs;

(b) EL is one of the factors that determine business performance. Although EL is crucial, it cannot stand alone to give optimum impact on performance. Therefore, it is expected that EL best be accompany with other intangible factors such as the intellectual capital and organizational capabilities to influence MSEs performance in recent era. Based on the narrative review, the $E L$ is one the valuable intangible factors, which relate to the quality of entrepreneurs' leadership. The EL should be accompanied with other intangible resources such as the human, structural and relational capitals, that represent the components to be managed by the entrepreneurial leaders in creating superior performance for the MSEs context;

(c) Based on the review, EL can be treat as a critical independent variable as well the moderating and mediating variable within the scope of the process model relationships. In certain process, EL play role as the mediating that mediates relationship between two or more causal-effect relationship, while in other modes it may mitigate the effect of certain 
relationships. Thus, roles may differ across different types and natures of relationships posited by the study;

(d) EL is a concept that can be influence by cultural factor of the particular context. As far as leadership and entrepreneurship are concerned, both concepts are closely tied to the culture of the particular context. EL may be high or low in certain culture and across demographic differences. Thus, it is worth exploring EL among different demographic and cultural groups or contexts. Specifically, it is worth exploring EL within the context of micro and small enterprises in developing countries, such as Malaysia, because the context may lead towards interesting insights in terms of revitalising the MSEs performance during and post crisis through effective leadership;

(e) EL is an evolving field. There are many potential studies can be initiated to enrich the knowledge related to EL through various perspectives including to strengthen the measurement of the concepts. This review serves as a catalyst towards more robust studies pertaining to EL from various management perspectives in line with current turbulent and competitive business environment.

Therefore, the above point set the way to go for EL research agenda by future studies.

\section{Conclusion}

EL is a leadership concept most often recommended for a dynamic and turbulent environment. Within the scope of turbulence faced by most MSEs, especially in the post COVID-19 era, the ability to recover must be initiated by a strong leadership best implemented through the EL concept. The entrepreneurial leader play pivotal role in enacting new environment not only for the business entity but also for the entire society. EL has a potential to emerge as an established field; thus, it is worth exploring by management researchers as well as implemented within the operation contexts of MSEs in developing countries. As far as EL dimensions are concerned, the concept is associated with the element of entrepreneurs' personal qualities and characters. Individual qualities such as innovation and pro-active support, being visionary, stimulating others, high confidence, analytical thinking and emotional intelligence become the pillars that represent the EL concept. As a conclusion, EL is summarized as leaders who demonstrate behaviours that promote an innovation-driven atmosphere and influence the members to belief in their own abilities, as well as to nurture commitment and sense of responsibility to contribute to business objectives.

\section{Acknowledgement}

This study is funded by the Malaysian Ministry of Higher Education through the Fundamental Research Grant Scheme (FRGS/1/2020/SSO2/UKM/02/4). This article represents as a part of the preliminary study for the project.

\section{References}

Omar, A. R. C., Ishak, S., \& Jusoh, M. A. (2020). The impact of COVID-19 Movement Control Order on SMEs' businesses and survival strategies. Geografia Malaysia Journal of Society and Space, 16(2), 139-150

Al Mamun, A., Ibrahim, M. D., Yusoff, M. N. H., \& Fazal, S. A. (2018). Entrepreneurial leadership, performance, and sustainability of micro-enterprises in Malaysia. Sustainability, 10(1591), 2-23. 
Audretsch, D. B., \& Thurik, A. R. (2000). What's new about the new economy? Sources of growth in the managed and entrepreneurial economies. Industrial and Corporate Change, 10(1), 267-311.

Arif, S., \& Akram, A. (2018). Transformational leadership and organizational performance. SEISENSE Journal of Management, 1(3), 59-75.

Bagheri, A., \& Harrison, C. (2020). Entrepreneurial leadership measurement: a multi dimensional construct. Journal of Small Business and Enterprise Development, 27(4), 659-679.

Bell, S. (2019). Task-Oriented vs People-Oriented Leadership Styles. Biz Fluent. https://bizfluent.com/info-12137619-taskoriented-vs-peopleoriented-leadershipstyles.html

Block, J. H., Fisch, C. O., \& Van Praag, M. (2016). The Schumpeterian entrepreneur: a review of the empirical evidence on the antecedents, behaviour and consequences of innovative entrepreneurship. Industry and Innovation, 24(1), 1-36. doi: 10.1080/13662716.2016.1216397

Cai Li, Makhdoom, H. U. R., \& Asim, S. (2020). Impact of Entrepreneurial leadership on innovative work behavior: examining mediation and moderation mechanisms. Psychology Research and Behavior Management, 13, 105-118.

Castro, M. P., \& Zermeno, M. G. G. (2020). Being an entrepreneur post COVID-19-resilience in times of crisis: a systematic review. Journal of Entrepreneurship in Emerging Economies. Vol. ahead-of-print No. ahead-of-print. https://doi.org/10.1108/JEEE-07-2020-0246

Eniola, A. A., \& Entebeng, H. (2015). Government policy and performance of Small and Medium Business Managament. International Journal of Academic Research in Business and Social Sciences, 5(2), 237-248.

Fairlie, R. W. (2020). The impact of COVID-19 on small business owners: evidence of early stage losses from the April 2020 current population survey. NBER Working Paper Series. Working Paper 23709. Cambridge: National Bureau of Economics Research https://www.nber.org/system/files/working_papers/w27309/w27309.pdf

Ferrari, R. (2015). Writing narrative style literature review. Medical Writing, 24(4), 230-235.

Filser, M., Kraus, S., Roig-Tierno, N., Kailer, N., \& Fischer, U. (2019). Entrepreneurship as cataylst for sustainable development: Opening the Black Box. Sustainability. 2019 (11) (4503): 1-18.

Gleeson, B. (2017). How value based leadership transforms organizational culture. https://www.inc.com/brent-gleeson/how-values-based-leadership-transformsorganizational-cultures.html

Gupta, V., MacMillan, I. C., \& Surie, G. (2004). Entrepreneurial leadership: developing and measuring a cross-cultural construct. Journal of Business Venturing, 19(2004), 241-260.

Harrison, C., Paul, S., \& Burnard, K. (2019). Entrepreneurial leadership: a systematic literature review. International Review of Entrepreneurship, 14(2), 235-264.

Heslina, Payangan, O. R., Taba, M. I., \& Pabo, M. I. (2016). Factors affecting the business performance of the micro, small and medium enterprises in creative economic sector in Makassar, Indonesia. Scientific Research Journal, IV(1), 41-49.

Jacobs, E., \& Mafini, C. (2019). Transactional leadership, supply chain quality and businessperformance in the fast moving consumer good industry. Journal of Transport and Supply Chain Management, 13(0) A442, https://doi.org/10.4102/jtscm.v13i0.442

Jaimovich, E. (2010). Adverse selection and entrepreneurship in a model of development. The Scandinavian Journal of Economics, 112(1), 77-100. 
Jing, F. F. (2017). Leadership paradigms and performance in small service firms. Journal of Management and Organization, 24(03), 339-358.

Karim, M. M., Latif, W., \& Choudhury, M. M. (2019). The art of developing Entrepreneurial Leadership. ACBSP Annual Conference-2019, 1-12.

Khan, Z. A., Hawaz, A. \& Khan I. (2016). Leadership theories and styles: A literature review. Journal of Resources and Development, 16, 1-7

Leitch, C. M., \& Volery, T. (2017). Entrepreneurial leadership: Insights and directions. International Small Business Journal, 35(2), 147-156.

Madanchian, M., Hussein, N., Noordin, F., \& Taheerdoost, H. (2016). Effects of leadership on organizational performance. Economics and Education, 115-119. https://www.researchgate.net/publication/305323612_Effects_of_Leadership_on_or ganizational_Performance

Ndofirepi, T. M. (2020). Relationship between entrepreneurship education and entrepreneurial goal intention: psychological traits as mediators. Journal of Innovation and Entreprneurship, 9(2), 1-20.

Paudel, S. (2019). Entreprneurial leadership and business performance. South Asian Journal of Business Studies, 8(3), 348-369.

Radzi, K. M., Mohd. Nor, M. N., \& Ali, S. M. (2017). The impact of internal factors on small business success: a case of small enterprises under the FELDA scheme. Asian Academy of Management Journal, 22(1), 27-55.

Sandybayez, A. (2019). Impact of effective entrepreneurial leadership style on organizational performance: critical review. International Journal of Economics and Management, 1(1), 47-55.

Sawaen, F. A. A., \& Ali, K. A. M. (2019). The impact of entrepreneurial leadership and learning orientation on organizational performance of SMEs: the mediating role of innovation capacity. Management Science Letters, 10(2020), 369-380.

Senthilkumar, K. (2020). The influence of entrepreneurial leadership in the performance of micro and small enterprises the case for Eastern Tigray, Ethiopia. SAMVAD:SIBM Pune Research Journal, XXI, 1-15.

Śledzik, K. (2013). Schumpeter's view on innovation and entrepreneurship. SSRN Electronic Journal. DDOI: 10.2139/ssrn.2257783.

Taylor, D. H. (2011). The power of value-based leadership. https://www.taiinc.com/wpcontent/uploads/2018/01/The-Power-of-Values-Based-Leadership.pdf

Tsetim, J. T., Asenge, E. L., \& Adudu, C. (2020). Entrepreneurial leadership and performance of small and medium scale enterprises in Benue State, Nigeria. Global Scientific Journal, 8(1), 2337-2347.

Van Zyl, H. J. C., \& Mathur-Helm, B. (2007). Exploring a conceptual model, based on the combined effects of entrepreneurial leadership, market orientation and relationship marketing orientation on South Africa's small tourism business performance. South African Journal of Business Management, 38(2), 17-24.

Ximenes, M., Supartha, W. G., Dewi, M. I. G. A., \& Sintaasih, D. K. (2019). Entrepreneurial leadership moderating high performance work system and employee creativity on employee performance. Cogent Business and Management, 2019(6), 1-12.

Yang, J., Pu, B., \& Guan, Z. (2019). Entrepreneurial leadership and turn over intention of employees: the role of affective commitment and person-job fit. International Journal of Environmental Research and Public Health, 2019 (6), 2-17. 